Ann. Zootech., I968, 17 (3), 34I-342.

NoTE

\title{
PIGMENTATION BRUNE DES COQUELETS ET CROISSANCE EN POIDS
}

\author{
P. MÉRAT \\ Station de Génétique animale, \\ Centre national de Recherches zootechniques, 78-Jouy-en-Josas \\ Institut national de la Recherche agronomique
}

Le plumage des coqs comporte assez souvent une pigmentation marron-brun, non confondue avec le "doré ", répartie sur le dos et le dessus des ailes, très variable en étendue. Divers génotypes permettent cette coloration. Nous avions passé brièvement en revue (MÉ,RAT, I955) les auteurs qui l'ont décrite dans des races ou croisements divers. Son déterminisme génétique n'est que partiellement connu. D'après KImBALL (I962), son apparition serait liée à la présence du gène $e^{+}$. D'autre part, une suggestion de Cock et PEAsE (I95I), et nos propres observations (MÉrat, I955) indiquent qu'une double dose du gène $S$ ("argenté " lié au sexe) la réduit fortement.

Dans une population issue à l'origine d'un croisement entre Rhode-Island et Gâtinaise, une partie des descendants mâles colorés possédait cette pigmentation avec une étendue et une intensité variables. Nos observations étaient limitées aux animaux de constitution Ss pour le couple d'allèles " argenté-doré ), car, parallèlement à la réduction de cette pigmentation indiquée plus haut en présence du génotype SS, elle peut être difficile à distinguer de la coloration générale chez des coqs ss.

Nous avons classé les animaux, à vue, en deux groupes, ceux possédant la coloration "brun-marron " à des degrés divers, et ceux ne la présentant pas d'une façon visible.

Les poids atteints à l'âge de 8 semaines ont été comparés pour ces deux groupes, en ne retenant que les familles de frères contenant des coquelets des deux catégories.

Sept années permettaient cette comparaison : dans chacune sans exception, les coquelets avec pigment brun avaient un poids à 8 semaines supérieur aux autres en moyenne. 
Sur l'ensemble des années, les poids moyens sont les suivants :

TABLEAU I

\begin{tabular}{c|c|c|c}
\multicolumn{2}{c}{$\delta$ s sans pigment brun } & \\
\hline Nombre & Poids moyen $(\mathrm{g})$ & Nombre & Poids moyen (g) \\
\hline 338 & 668,5 & 282 & 711,9 \\
\hline
\end{tabular}

La différence sur l'ensemble est hautement significative $(\mathrm{P}<0, \mathrm{OI})$.

D'autre part, la variance intra-générations du poids pour les coqs avec pigment brun est un peu inférieure à celle des mâles sans pigment brun. Si l'on considère les coefficients de variation, la différence est plus marquée.

On ne peut conclure si cette croissance plus rapide et plus homogène est une action pléiotropique des gènes responsables du pigment, ou si ces derniers sont simplement liés à des gènes "de croissance ", ou encore ne se manifestent qu'à partir d'un certain stade de développement de l'animal.

Regu pour publication en septembre $\mathrm{I} 968$.

\section{SUMMARY}

RELATIONSHIP BETWEEN GROWTII RATE

AND " CHESNUT " PIGMENT IN COCKERELS

In a strain of chickens, $\mathrm{s}$ s cockerels with " chesnut " pigment in the plumage were found to be significantly heavier at 8 weeks than their unpigmented full brothers. This may be due either to a pleiotropic effect of the relevant colour genes, or to linked genes, or to genes having no effect until a certain stage of maturity.

\section{RÉFÉRENCES BIBLIOGRAPHIQUES}

Cock A. G., Pease M., I951. Ia génétique du dessin P’ile blanc sur la volaille. C.r. IXc Congrès mondial d'Aviculture, 1, 47-51.

Kimbali, E., 1952. Genetic relation of extended black to wild type plumage pattern in the fowl. Poult. Sci., 31, 73-78.

Mérat P., I955. La race Gâlinaise : Étude de sa variabilité génétique en vue d'obtenir des croisements homogènes. Ann. Zoolech., 4, 259-283. 